\title{
Paleomagnetic reorientation of San Andreas Fault Observatory at Depth (SAFOD) core
}

\author{
Josep M. Parés, ${ }^{1}$ Anja M. Schleicher, ${ }^{1,2}$ Ben A. van der Pluijm, ${ }^{1}$ and Stephen Hickman ${ }^{3}$ \\ Received 19 June 2007; revised 14 August 2007; accepted 4 December 2007; published 23 January 2008.
}

[1] We present a protocol for using paleomagnetic analysis to determine the absolute orientation of core recovered from the SAFOD borehole. Our approach is based on determining the direction of the primary remanent magnetization of a spot core recovered from the Great Valley Sequence during SAFOD Phase 2 and comparing its direction to the expected reference field direction for the Late Cretaceous in North America. Both thermal and alternating field demagnetization provide equally resolved magnetization, possibly residing in magnetite, that allow reorientation. Because compositionally similar siltstones and fine-grained sandstones were encountered in the San Andreas Fault Zone during Stage 2 rotary drilling, we expect that paleomagnetic reorientation will yield reliable core orientations for continuous core acquired from directly within and adjacent to the San Andreas Fault during SAFOD Phase 3, which will be key to interpretation of spatial properties of these rocks. Citation: Parés, J. M., A. M. Schleicher, B. A. van der Pluijm, and S. Hickman (2008), Paleomagnetic reorientation of San Andreas Fault Observatory at Depth (SAFOD) core, Geophys. Res. Lett., 35, L02306, doi:10.1029/2007GL030921.

\section{Introduction}

[2] The San Andreas Fault Observatory at Depth (SAFOD) project is being conducted to study the physical and chemical processes controlling faulting and earthquake generation within a major plate-bounding fault [e.g., Hickman et al., 2004]. SAFOD is located $9 \mathrm{~km}$ NW of Parkfield, California, and penetrates a section of the fault that is currently moving through a combination of repeating microearthquakes and fault creep. During SAFOD Phases 1 and 2 in the summers of 2004 and 2005, SAFOD was drilled vertically to a depth of $1.5 \mathrm{~km}$ and then deviated at about $55^{\circ}$ to vertical, passing through the entire San Andreas Fault Zone to a vertical depth of $3.1 \mathrm{~km}$. The SAFOD borehole was rotary drilled, comprehensive cuttings were obtained and a real-time analysis of gases in the drilling mud was carried out. In addition, $\sim 60 \mathrm{~m}$ of spot cores were obtained during Phases 1 and 2 in the shallow granite and deeper sedimentary rocks penetrated by SAFOD. A suite of open-hole geophysical measurements were also made over essentially the entire depth of the hole.

\footnotetext{
${ }^{1}$ Department of Geological Sciences, University of Michigan, Ann Arbor, Michigan, USA.

${ }^{2}$ Now at Geology Department, University of Erlangen-Nuernberg, Erlangen, Germany.

${ }^{3}$ U.S. Geological Survey, Menlo Park, California, USA.
}

Copyright 2008 by the American Geophysical Union. 0094-8276/08/2007GL030921
During Phase 3 of SAFOD, which is being conducted in the summer of $2007, \sim 600 \mathrm{~m}$ of continuous core will be acquired from directly within and adjacent to the active San Andreas Fault Zone in side tracks drilled off the existing borehole. These cores will be extensively tested in the laboratory to determine their mineralogy, geochemical composition, deformation mechanisms, frictional behavior and physical properties.

[3] Several physical properties measured in the core have a directional nature, including bedding, faults, veins, microfractures, seismic velocities, and permeability. Reconstructing the in-situ orientation of recovered drill core (termed here reorientation) is hence of great importance when interpreting the structural, deformational and physical properties of fault and country rocks. Paleomagnetism can be used to reconstruct the absolute orientation of the core by providing a reference direction relative to geographic coordinates. The paleomagnetic core reorientation method has been successfully used for a number of years [e.g., Fuller, 1969; Kodama, 1984; Shibuya et al., 1991] and offers distinct advantages over other methods. Measurements are made on samples from the cores following recovery from the borehole, and hence do not have any impact on the coring process itself (unlike, for example, scribing techniques that can lead to core jamming and poor recovery, especially in highly fractured rock). Because cores are oriented one piece at a time, paleomagnetic core reorientation is generally more reliable than traditional scribed-core techniques, which require extremely precise correlations between core depths and orientation data acquired with a downhole orientation tool. This technique can be applied to recently drilled cores and stored old cores, even in the absence of real-time core orientation or borehole image log data. In this paper we report results of a paleomagnetic and mineralogic (SEM) study aimed at providing a reliable method for SAFOD core reorientation.

\section{Geological Setting}

[4] The SAFOD Main Hole is drilled near Parkfield, California, in the area where Salinian basement rocks are juxtaposed with Franciscan complex rocks (Figure 1). In this area in the Coast Ranges, the Salinian block is composed of Cretaceous granite, and the Franciscan complex of an assemblage of metasedimentary rocks and serpentinites that are unconformably overlain by sedimentary rocks of the Great Valley sequence [Dickinson, 1966; Page et al., 1998; Sims, 1990; Rymer et al., 2003].

[5] Phase 1 and 2 drilling (from top to bottom) revealed a succession of sediments of likely Tertiary age (0 to $760 \mathrm{~m})$, granite and granodiorite (760 to $1920 \mathrm{~m}$ ), arkosic and lithic arenites $(1920$ to $\sim 3150 \mathrm{~m})$, and a siltstone and shale 

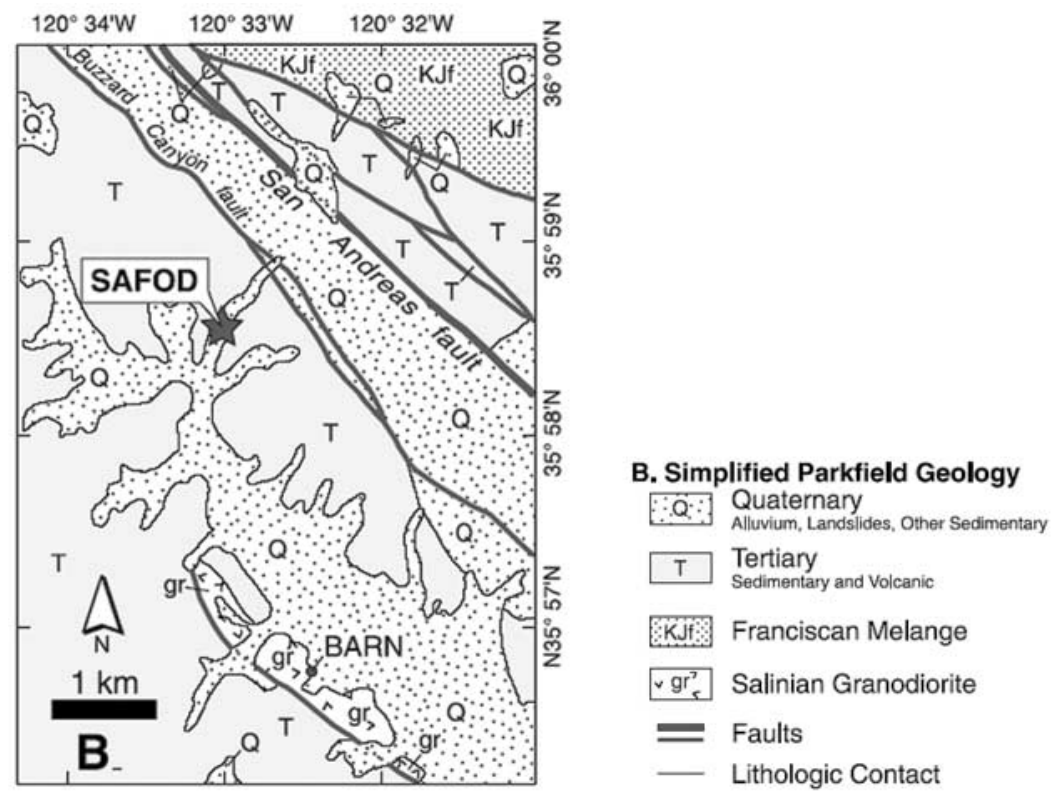

Figure 1. Simplified geological map of the area around SAFOD drill site in Parkfield, CA, showing the main geologic units and major faults (modified from Blythe et al. [2004]).

sequence from $3150 \mathrm{~m}$ to $3992 \mathrm{~m}$ (see http://www.icdponline.de/sites/sanandreas/index/). Details on the lithology are given by Almeida et al. [2005], Solum et al. [2006], and K. K. Bradbury et al. (submitted manuscript, 2007). Samples for paleomagnetic analysis are from the siltstone and shale sequence that begins at $3150 \mathrm{~m}$. Recent analysis on samples from these sediments revealed an assemblage of benthic fossils characteristic of the Great Valley sequence, suggesting an early Maastrichtian to late Campanian age.

\section{Methods}

[6] Cores from Phase 1 and Phase 2 were sampled at the TAMU Repository after detailed description of lithology and structural features. Visual inspection of the drilled material allowed the trace of an arbitrary 'common reference line' (CRL) along core segments to be re-oriented [Almeida et al., 2005]. Orientation and location of samples for paleomagnetism were taken in relation to the CRL. Samples were obtained using two different methods, in- cluding a standard $1^{\prime \prime}$ diameter drill bit and cutting $\sim 8 \mathrm{cc}$ cubes with a regular rock saw that was equipped with a nonmagnetic blade. All specimens were processed using paleomagnetic techniques at the Rock and Paleomagnetism Laboratory of the University of Michigan. A 3-axis cryogenic magnetometer $(2 \mathrm{G})$ was used to measure the Natural Remanent Magnetization (NRM) and the remanence upon demagnetization. Both thermal (ASC) and alternating field (SI-4, Sapphire Instr.) demagnetization procedures were used to isolate the magnetic components. The paleomagnetic equipment is housed in a shielded room with a residual field $<200 \mathrm{nT}$. Directional analysis was carried out by principal component analysis after progressive step-wise demagnetization. Fisher's statistics was used to compute mean directions and associated 95\% confidence cones (Table 1).

[7] A set of samples was prepared for Scanning Electron Microscopy (SEM) and X-ray diffraction analysis (XRD). Carbon-coated, polished thin sections were used for backscattered imaging using a Hitachi S-3200N Electron

Table 1. Paleomagnetic Results ${ }^{\mathrm{a}}$

\begin{tabular}{|c|c|c|c|c|c|c|c|c|c|c|}
\hline \multicolumn{5}{|c|}{ Sample Details } & \multicolumn{3}{|c|}{ Paleomagnetic Directions } & \multicolumn{3}{|c|}{ Bedding Plane } \\
\hline Sample & Box & Run & From Depth & To Depth & Dec & Inc & $\alpha_{95}$ & $\theta$ & St & Dip \\
\hline SA1-A & 2 & 7 & $13095^{\prime} 2.5^{\prime \prime}$ & $13095^{\prime} 4^{\prime \prime}$ & 203.7 & 68.6 & & 144 & 324 & 34 \\
\hline SA1-B & $"$ & " & & & 197.0 & 74.5 & & "I & & \\
\hline MEAN & & & & & 200.9 & 71.6 & 13.7 & & & \\
\hline SA2-A & 3 & 7 & $13095^{\prime} 6.5^{\prime \prime}$ & $13095^{\prime} 7.5^{\prime \prime}$ & 338.4 & 59.1 & & & & \\
\hline SA2-B & $"$ & $"$ & & & 338.0 & 65.4 & & & & \\
\hline MEAN & & & & & 338.3 & 62.3 & 13.8 & & & \\
\hline SA3-A & 3 & 7 & $13097^{\prime} 9^{\prime \prime}$ & $13097^{\prime} 10^{\prime \prime}$ & 144.7 & 84.7 & & 110 & 290 & 35 \\
\hline SA4-A & 3 & 7 & $13097^{\prime} 10.5^{\prime \prime}$ & $13098^{\prime} 0^{\prime \prime}$ & 125.7 & 68.3 & & " & $"$ & $" 1$ \\
\hline SA4-B & $" \prime$ & " & " & " & 119.2 & 72.0 & & $" 1$ & " & " \\
\hline SA5-A & 3 & 7 & $13098^{\prime} 2.5^{\prime \prime}$ & $13098^{\prime} 4^{\prime \prime}$ & 121.8 & 59.5 & & " & " & " \\
\hline SA5-B & II & " & & & 106.1 & 65.0 & & $\prime \prime$ & " & $" \prime$ \\
\hline MEAN & & & & & 119.5 & 70.2 & 9.6 & & & \\
\hline
\end{tabular}

${ }^{\mathrm{a}} \mathrm{Dec} / \mathrm{Inc}$, Paleomagnetic declination and inclination; $\alpha_{95}$, cone of $95 \%$ of confidence; "Mean" refers to the fisherian mean paleomagnetic direction; $\theta$, angular distance between the common reference line and bedding strike; St/Dip, strike and dip of bedding. 

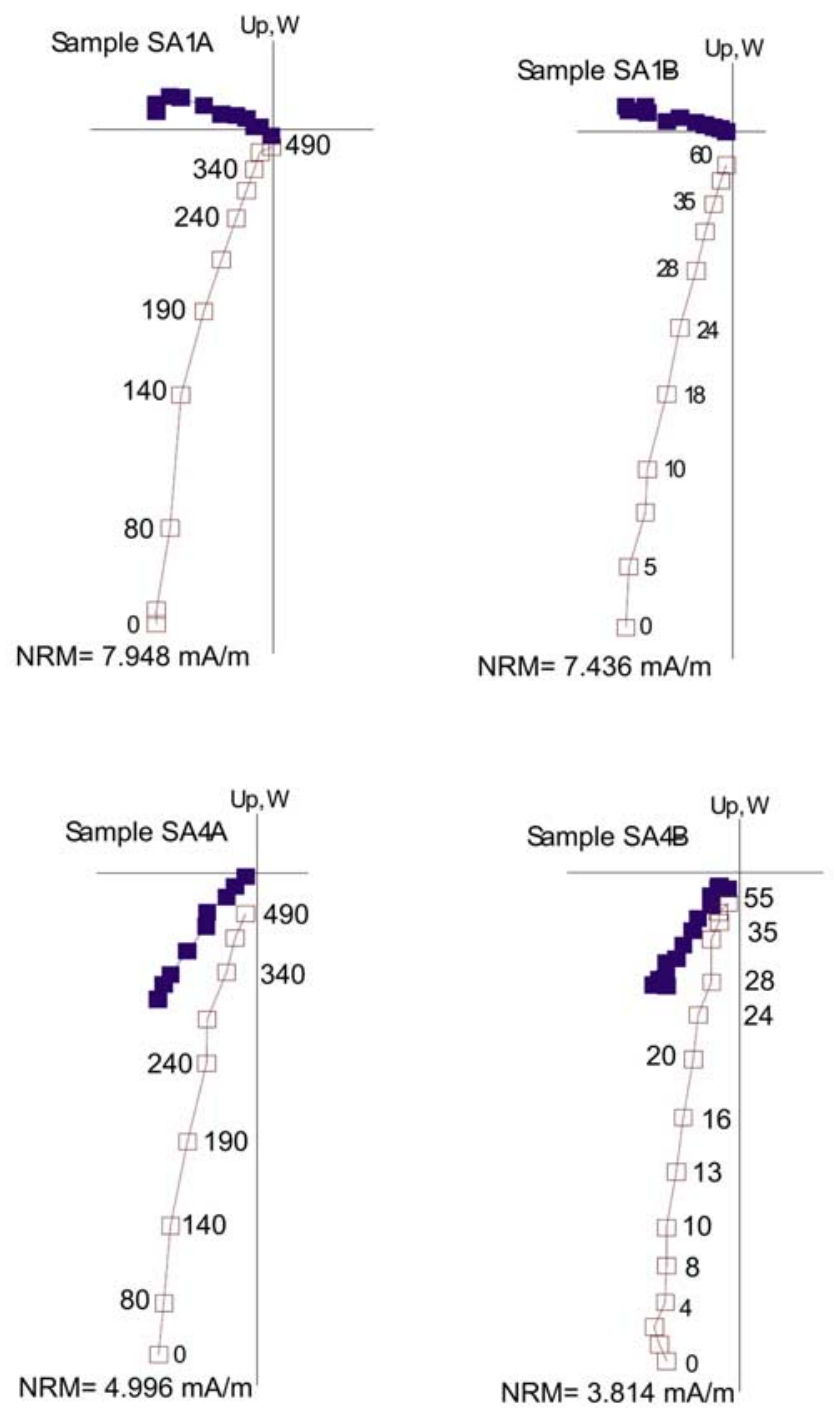

Figure 2. Results of progressive thermal and alternating field demagnetization displayed by vector end point diagrams [Zijderveld, 1967] of representative samples of Great Valley sediments. Each data point represents the projection of the magnetization vector for individual demagnetization steps projected onto the horizontal (solid symbols) and vertical (open symbols) plane. Numbers adjacent to data points indicate the alternating field peak value (right) or the temperature (left). NRM intensity is also given. Diagrams shown in core coordinates.

microscope at EMAL of the University of Michigan. Semiquantitative analysis of mineral composition was obtained by energy-dispersive-spectroscopy (EDS). X-ray diffraction (XRD) analyses of random powder and texture preparations followed the analytical methods described by Moore and Reynolds [1997]. The analysis was obtained with a Scintag Powder XRD for bulk -and clay mineralogy.

\section{Paleomagnetic Results}

[8] The sediment samples obtained from Phase 2 core at a depth between 3991.36 to 3992.58 meters (Table 1), include siltstones and fine-grained sandstones, and details are given by K. K. Bradbury et al. (submitted manuscript, 2007). NRM intensities of the sediments average $5.5 \mathrm{~mA} / \mathrm{m}$, and low-field bulk susceptibility around $290 \times 10^{-6}$ SI. Progressive thermal demagnetization shows a steady decay of magnetization with increasing temperature (Figure 2). Samples generally display very little or no viscous overprint, and the magnetization is reduced to $<10 \%$ of its initial value at $490^{\circ} \mathrm{C}$. Alternating field demagnetization is equally efficient in revealing the paleomagnetic direction (Figure 2), with intensity reduced to $<10 \%$ by $60 \mathrm{mT}$. Combined, these observations are consistent with the presence of magnetite as the remanence carrier in these sediments.

[9] Because the goal of this study to determine the steps for paleomagnetic orientation of the SAFOD core into its pre-drilling position, we divided the paleomagnetic samples in two different sets, owing to the common reference line (Table 1). Although samples SA1 and SA2 share a common reference line, the latter was excluded from our analysis because bedding could not be unambiguously determined. Samples SA3, SA4 and SA5 span a depth of $3992 \mathrm{~m}$ and share a common reference line (Table 1).

\section{Mineralogy}

[10] The whole rock powder X-ray diffraction (XRD) analysis reveals a variety of mineral assemblages in the rock samples between 3991 and $3992 \mathrm{~m}$ which are rather constant with depth. The primary constituents are quartz, feldspar (K-feldspar and plagioclase) and mica (chlorite, biotite and/or muscovite and/or illite), secondary phases are calcite, zeolite (laumontite) and pyrite. The clay size fraction $(<2 \mu \mathrm{m})$ is dominated by chlorite, illite and/or muscovite, quartz and albite.

[11] The backscattered SEM/EDS analyses on thin sections confirm the mineralogy measured by XRD; calcite mainly occurs in small veins, and laumontite could be detected predominantly as pore filling minerals. Pyrite is relatively abundant in all samples, and occurs mainly as flattened framboids consisting of small cubic crystals up to about $3 \mu \mathrm{m}$ in average size (Figure 3a). Other individual cubic pyrite grains are scattered through the whole samples and additional elongated pyrite (about $2 \mu \mathrm{m}$ in length) grow coeval with chlorite and biotite minerals. Based on EDS spectra, these minerals are pristine and show no alteration or contamination with other elements, which supports the primary origin of a magnetic remanence in all samples. Accessory minerals are apatite, rutile, magnetite, ilmenite and titanite. Magnetite is extremely small grained $(<1 \mu \mathrm{m})$ and appears only in very low concentration. However, an intergrowth of this very small grained magnetite with titanite minerals could be detected due to the presence of a distinct iron-peak in some of the titanite minerals (Figure 3a). Also, small magnetite grains with characteristic cubic shapes $(<1 \mathrm{~mm})$ are intergrown aggregates with quartz (Figure $3 \mathrm{~b}$ ). These observations suggest that (lowTi) magnetite is likely the remanence carrier in the sedimentary rock samples investigated.

\section{Re-Orientation Parameters and Steps}

[12] Based on the presence of a well-defined remanence isolated over a range of $\sim 200$ to $490^{\circ} \mathrm{C}$, we developed a 

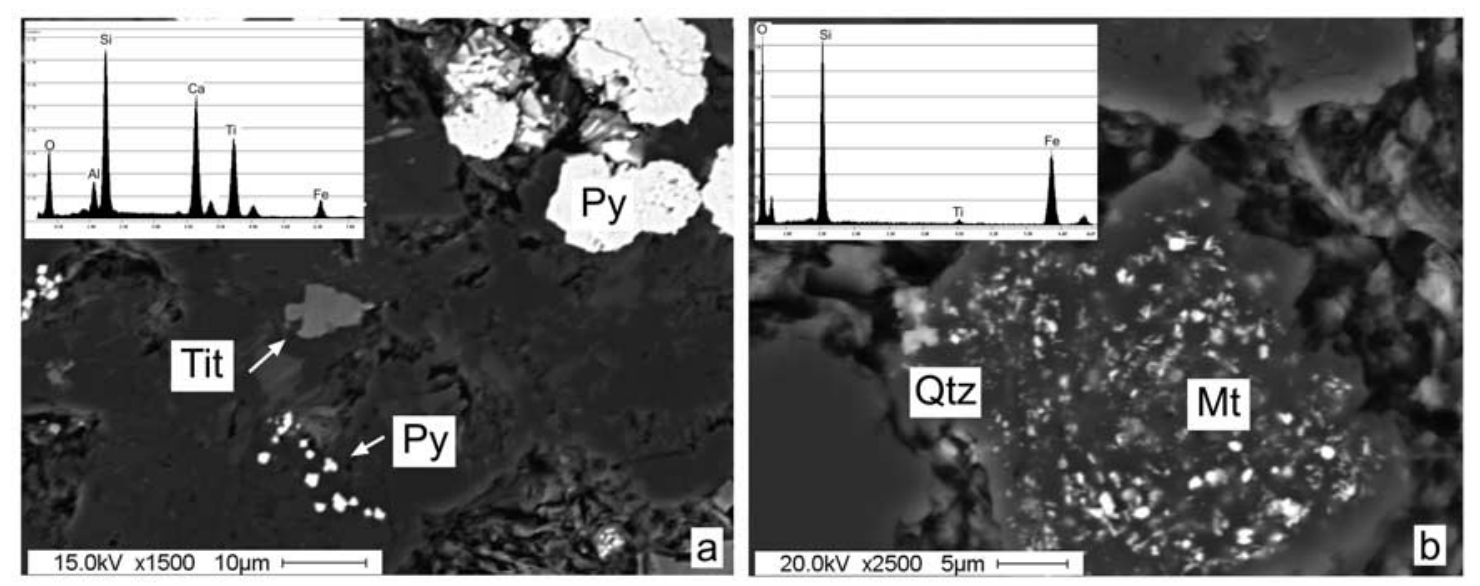

Figure 3. Backscattered electron microscopy images (BSE) of the mud-rocks at $3992 \mathrm{~m}$ MD (Sample SA-4A, Table 2). (a) Pristine pyrite occurs as framboids and individual cubic grains. Iron peak in titanite as possible indication for small magnetite grains. (b) Small grains $<1 \mu \mathrm{m}$ in size with a clear Fe peak on a quartz grain as indication of small magnetite components.

reorientation protocol. A basic assumption in our approach is that the remanence in the sediments is of primary origin, as suggested by the X-ray analysis. Notice that standard "field tests" (i.e., fold test, conglomerate test, etc.) to determine the relative age of the magnetization are not feasible with the available material. Ongoing, more detailed rockmagnetic analysis will help in testing our assumption.

[13] The paleomagnetic results are compared with the reference directions from the apparent polar wander path, constrained by the age of these samples. Restoring the core orientation to geographic coordinates involves: (1) Computing the mean paleomagnetic direction for samples sharing a common reference line (Table 1). Samples SA2 were excluded from our analysis as bedding attitude could not be unambiguously determined from visual inspection of the core. Samples SA3 through SA5 are grouped as they share a common reference line. (2) Comparison with the Late Cretaceous reference field based on the paleopole of Besse and Courtillot [2002] for North America, transferred to the latitude and longitude of the SAFOD drilling site (Table 2). (3) Determining the (rotated) orientation of bedding (dip direction and dip angle), relative to the main core axis. Note that, unless bedding is perpendicular to the core long axis, its trace will produce a sinusoidal shape on the core wraparound maps. This is particularly apparent for samples at a depth of $\sim 3992.3$. We determine the dip angle from the amplitude of the sinusoidal trace. This angle is referenced to the plane perpendicular to the main core and the dip direction is then measured relative to the common reference line. Because the diameter of the core is known, all variables including bedding dip angle and dip direction can be determined, as indicated in Table 1. (4) Because the trend and plunge of the main core along the sampled interval are known http://www.icdp-online.de/sites/ sanandreas/index/), we can now restore both paleomagnetic direction $(\mathrm{P})$ and bedding pole $\left(\mathrm{S}_{0}\right)$ to account for the core trend and plunge.

[14] This procedure involves rotating both $\mathrm{P}$ and $\mathrm{S}_{0}$ by the same amount of the core dip angle toward its plunge direction, involving a rotation of $\mathrm{P}$ and $\mathrm{S}_{0}$ by the amount of the main core plunge $\left(30^{\circ}\right.$ to an azimuth of $\left.\mathrm{N} 20^{\circ} \mathrm{E}\right)$. After rotation we obtain a new direction for both the paleomagnetic remanence and pole to bedding, labeled $\mathrm{P}^{\prime}$ and $\mathrm{S}_{0}^{\prime}$ in the plot (Figure 4). Because we know $\mathrm{P}$ and $\mathrm{S}_{0}$ relative to the axis of the core, we can now trace two small circles that contain all possible locations of $\mathrm{P}$ and $\mathrm{S}_{0}$ in geographic coordinates. On a lower hemisphere equal angle (Wulff) projection, these two circles describe two small circles around the core axis (Figure 4). Whereas the 'true' orientation of $\mathrm{P}^{\prime}$ and $\mathrm{S}_{0}{ }^{\prime}$ can lie anywhere on their respective small circles, there is one particular location where, upon restoring bedding to the horizontal (moving its pole $\mathrm{Sc}$ to the vertical), the measured paleomagnetic direction Pc will coincide (within the margin of error) with the expected paleomagnetic reference direction $\left(\mathrm{P}_{\mathrm{E}}\right)$. The optimal location of $\mathrm{P}^{\prime}$ and $\mathrm{S}_{0}{ }^{\prime}$ are found iteratively by restoring $\mathrm{S}_{0}{ }^{\prime}$ to vertical (so bedding is horizontal) and rotating $\mathrm{P}^{\prime}$ by the same angular distance, until it lies within the error margin of $\mathrm{P}_{\mathrm{E}}$. For an arc of $\sim 80$ degrees, a path of paleomagnetic directions after bedding correction for a set of solutions is shown (Figure 4). Along such a path, there is a solution labeled Pc that corresponds to the paleomagnetic direction, which, after bedding correction, conforms the expected reference direction $\mathrm{P}_{\mathrm{E}}$. This solution gives the amount and sense of rotation to correct the segment of the main core containing the samples analyzed, and hence to refer it to geographic coordinates. For the studied interval, this condition is met when the core interval containing samples SA3, SA4, and SA5 is rotated clockwise by 60 degrees and the interval containing sample SA1 by 50 degrees. To a large extent, the agreement between observed and expected directions is determined by the accuracy by which bedding attitude can be measured from the wrap-around maps. The angle between the observed paleomagnetic direction and

Table 2. Main Core Data

\begin{tabular}{|c|c|c|c|c|c|c|c|c|c|}
\hline \multirow{2}{*}{\multicolumn{3}{|c|}{ Main Core Data }} & \multirow{2}{*}{\multicolumn{2}{|c|}{$\begin{array}{l}\text { SAFOD } \\
\text { Location }\end{array}$}} & \multicolumn{5}{|c|}{ Paleomagnetic Reference } \\
\hline & & & & & & Pole & & Directic & \\
\hline Azimuth & Plng & Diameter & Lat, N & Long, E & Lat, N & Long, E & $\alpha_{95}$ & Dec & Inc \\
\hline $\mathrm{N} 20 \mathrm{E}$ & 30.2 & $77 \mathrm{~mm}$ & 36 & 239.45 & 74.7 & 207.4 & 6 & 347.8 & 66.1 \\
\hline
\end{tabular}




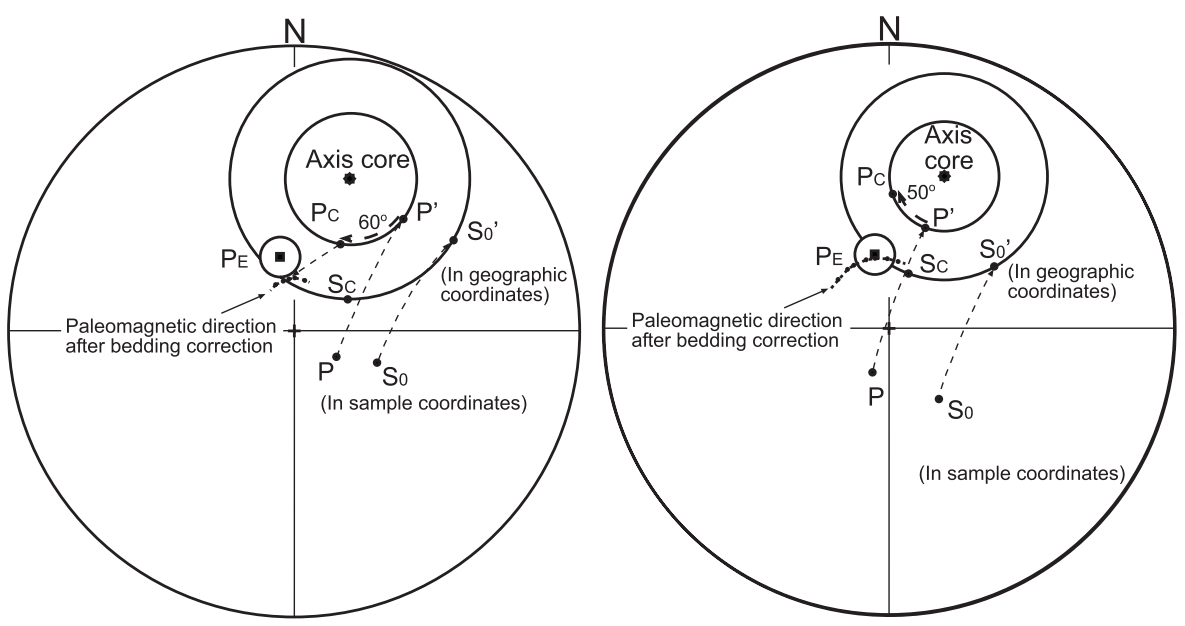

Figure 4. Lower-hemisphere, equal-angle (Wulff) projection of paleomagnetic results. "Axis core" shows the orientation of the main core; $\mathrm{P}$ and $\mathrm{S}_{0}$ are the paleomagnetic direction and pole to bedding in sample coordinates, respectively; $\mathrm{P}^{\prime}$ and $\mathrm{S}_{0}^{\prime}$ are paleomagnetic direction and pole to bedding back tilted geographic coordinates. The "true" orientation of $\mathrm{P}^{\prime}$ and $\mathrm{S}_{0}^{\prime}$ lie on two respective small circles centered on the orientation of the main core. Pc and Sc correspond to the position of the paleomagnetic direction and pole to bedding for which upon restoring bedding to the horizontal (moving Sc to the vertical), the measured paleomagnetic direction Pc coincides (within the margin of error) with the expected paleomagnetic reference direction $\left(\mathrm{P}_{\mathrm{E}}\right)$.

pole to bedding $(\Delta)$ should be, by definition, constant regardless of the "true" orientation of the main core. For an Upper Cretaceous Great Valley sedimentary rock (assuming no effects produced by inclination shallowing), the expected paleomagnetic inclination at the SAFOD location is $66^{\circ}$, which implies a value of $\Delta=24^{\circ}$. For the interval of sample SA1, $\Delta=27^{\circ}$ and that for samples SA3, SA4, and SA5 $\Delta=16^{\circ}$.

[15] Once the core-reorientation angles are determined, any directional property of the core can be restored. Using the rotation parameters in Figure 4, at a depth of $3991 \mathrm{~m}$ bedding is $\sim 324 / 34 \mathrm{SW}$ and at $3992.3 \mathrm{~m}$ is $\sim 290 / 35 \mathrm{SW}$, revealing strikes that are consistent with the local geology and the trace of the San Andreas fault at the surface.

\section{Concluding Remarks}

[16] This study documents the feasibility of using paleomagnetism for the reorientation of SAFOD core collected at selected intervals. Siltstones and fine grained sandstones from the Great Valley Sequence show a stable remanent magnetization with maximum unblocking temperatures just below the Curie point of magnetite. Also, our mineralogical study reveals the presence of intergrowth of cubic-shaped magnetite with quartz, and unaltered pyrite, chlorite and biotite, suggesting that the remanence in the siltstones is most likely primary in origin. Independent evidence that favors the primary origin of the magnetization is the value of the magnetic inclination. Hence, the angle $\Delta$, which is angle between the magnetic inclination and the bedding plane, is consistent with the predicted Late Cretaceous paleomagnetic field.

[17] The paleomagnetic direction and bedding plane orientation, both obtained from core, allow the orientation of core segments to be restored relative to the geographic coordinates. For the specific core intervals studied, a clockwise rotation of 60 and 50 degrees was required.
[18] After correction for core orientation, bedding strike of the Great Valley sequence conforms to the surface geology observations and the overall trace of the San Andreas Fault.

[19] Because compositionally similar siltstones and finegrained sandstones were encountered along the San Andreas Fault core during Stage 2 rotary drilling, we are confident that this paleomagnetic reorientation should provide reliable core orientations for additional samples collected during Phase 3 drilling.

[20] Acknowledgments. Research was supported by the National Science Foundation; EAR-0345985 and EarthScope O\&M. The personnel at the Gulf Coast Repository (College Station, TAMU), John Firth, Phil Rumford and Keith Gentry, were very helpful and patient with core sampling. We thank John Geissman and an anonymous reviewer for their thorough comments on an earlier version of the manuscript.

\section{References}

Almeida, R., J. S. Chester, F. M. Chester, D. L. Kirschner, T. Waller, and D. E. Moore (2005), Mesoscale structure and lithology of the SAFOD Phase I and II core samples, Eos Trans. AGU, 86(52), Fall Meet. Suppl., Abstract T21A-0454.

Besse, J., and V. Courtillot (2002), Apparent and true polar wander and the geometry of the geomagnetic field over the last $200 \mathrm{Myr}, J$. Geophys. Res., 107(B11), 2300, doi:10.1029/2000JB000050.

Blythe, A. E., M. A. d'Alessio, and R. Bürgmann (2004), Constraining the exhumation and burial history of the SAFOD pilot hole with apatite fission track and (U-Th)/He thermochronometry, Geophys. Res. Lett., 31, L15S16, doi:10.1029/2003GL019407.

Dickinson, W. R. (1966), Table Mountain serpentinite extrusion in California Coast ranges, Geol. Soc. Am. Bull., 77, 451-472.

Hickman, S., M. Zoback, and W. Ellsworth (2004), Introduction to special section: Preparing for the San Andreas Fault Observatory at Depth, Geophys. Res. Lett., 31, L12S01, doi:10.1029/2004GL020688.

Fuller, M. (1969), Magnetic orientation of borehole cores, Geophysics, 34, $772-774$.

Kodama, K. P. (1984), Paleomagnetism of granite intrusives from the Precambrian basement under eastern Kansas: Orienting drill-cores using secondary magnetization components, Geophys. J. R. Astron. Soc., 76, $273-287$.

Moore, D. E., and R. C. Reynolds (1997), X-Ray Diffraction and the Identification and Analysis of Clay Minerals, 2nd ed., 378 pp., Oxford Univ. Press, New York. 
Page, B. M., G. A. Thompson, and R. G. Coleman (1998), Late Cenozoic tectonics of the central and southern Coast Ranges of California, Geol. Soc. Am. Bull., 110, 846-876.

Rymer, M. J., R. D. Catchings, and M. R. Goldman (2003), Structure of the San Andreas fault zone as revealed by surface geologic mapping and high-resolution seismic profiling near Parkfield, California, Geophys. Res. Abs., 5, 13,523.

Shibuya, H., et al. (1991), Paleogene counterclockwise rotation of the Celebes Sea - Orientation of ODP cores utilizing the secondary magnetization, Proc. Ocean Drill. Program Sci. Results, 124, 519-523.

Sims, J. D. (1990), Geologic map of the San Andreas Fault in the Parkfield 7.5-minute Quad., Ca., scale 1: 24000, U.S. Geol. Surv. Misc. Field Stud. Map, $M F-2115$.

Solum, J. G., S. H. Hickman, D. A. Lockner, D. E. Moore, B. A. van der Pluijm, A. M. Schleicher, and J. P. Evans (2006), Mineralogical charac- terization of protolith and fault rocks from the SAFOD Main Hole, Geophys. Res. Lett., 33, L21314, doi:10.1029/2006GL027285.

Zijderveld, J. D. A. (1967), AC demagnetization of rocks: Analysis of results, in Methods in Paleomagnetism, edited by D. W. Collinson et al., pp. 254-286, Elsevier, New York.

S. Hickman, U.S. Geological Survey, 345 Middlefield Road, MS977, Menlo Park, CA 94025, USA.

J. M. Parés and B. A. van der Pluijm, Department of Geological Sciences, University of Michigan, 2534 C. C. Little Building, Ann Arbor, MI 481091063, USA. (jmpares@umich.edu)

A. M. Schleicher Geology Department, University of ErlangenNuernberg, Schloßgarten 5, D-91054 Erlangen, Germany. 